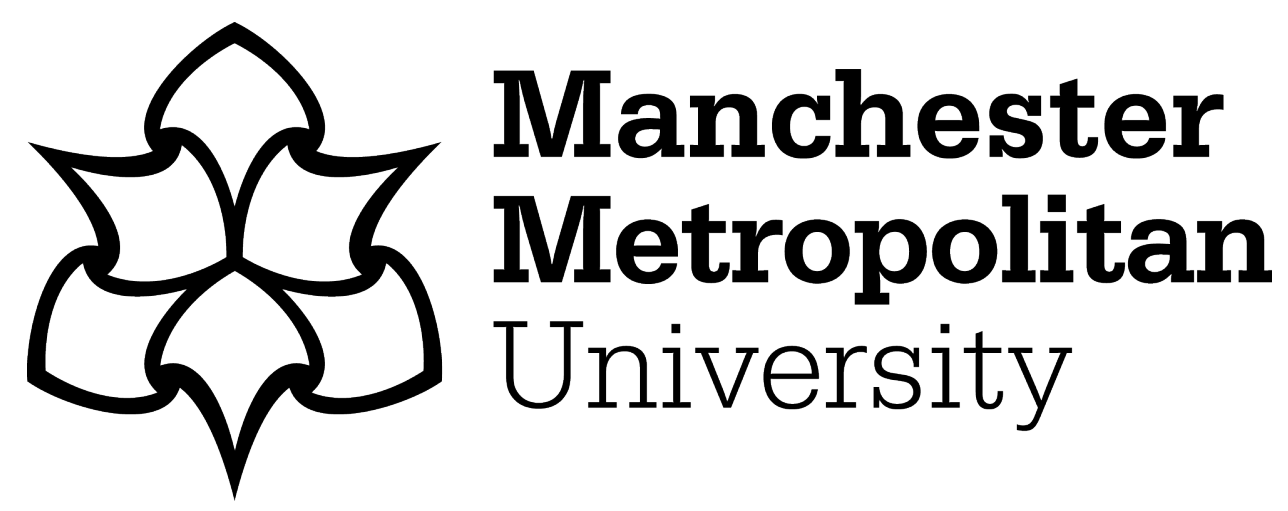

Schneider, J, Pollock, K, Wilkinson, S ORCID logoORCID: https://orcid.org/0000-0002-1564-5472, Perry-Young, L, Travers, C and Turner, N (2019) The subjective world of home care workers in dementia: an "order of worth" analysis. Home Health Care Services Quarterly, 38 (2). pp. 96-109. ISSN 0162-1424

Downloaded from: https://e-space.mmu.ac.uk/622762/

Version: Accepted Version

Publisher: Taylor \& Francis

DOI: https://doi.org/10.1080/01621424.2019.1578715

Please cite the published version 


\title{
The subjective world of home care workers in dementia: an "order of worth" analysis
}

\author{
Justine Schneider, $\mathrm{PhD}^{\mathrm{a}}$, Kristian Pollock, $\mathrm{PhD}^{\mathrm{b}}$, Samantha Wilkinson, $\mathrm{PhD}^{\mathrm{c}, \mathrm{d}}$, \\ Lucy Perry-Young, PhD ${ }^{c, e}$, Cheryl Travers, PhD $^{f}$, and Nicola Turner, PhD (0) \\ aSchool of Sociology and Social Policy, University of Nottingham, University Park, Nottingham, UK; \\ ${ }^{\mathrm{b} S}$ School of Health Sciences, University of Nottingham, Nottingham, UK; 'School of Sociology and Social \\ Policy, University of Nottingham, UK; ' ${ }^{\mathrm{S}} \mathrm{School}$ of Science and the Environment, Manchester

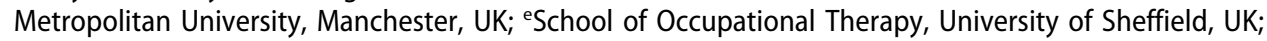 \\ fSchool of Business and Economics, Loughborough University, UK
}

\begin{abstract}
The perspective of domiciliary workers is needed to recruit a high-quality workforce and meet growing demand. An English ethnographic study yielded extensive insights. To structure analysis of the study data, we apply a method developed by political theorists Boltanski and Thévenot (2006) that identifies key variables in different values systems. This "orders of worth" framework is used to map out the distinctive features of the subjective world of home carers. The results can be drawn on to formulate recruitment and retention policies, to design reward strategies or to ensure that training and education opportunities engage effectively with the workforce.
\end{abstract}

\section{KEYWORDS}

Staff roles; quality of care; care issues of persons with dementia; dementia; social support

\section{Background}

There is a growing demand for care workers to look after rising numbers of frail, older people worldwide (Genet, Boerma, Kroneman, Hutchinson, \& Saltman, 2014; Prince et al., 2013; Stone, 2016; Skills for Care, 2017). The widespread promotion of community and family-based models of long-term care is predicated upon a supply of skilled support in domestic settings. In some country contexts live-in carers appear to be commonplace, for instance in Israel (Ben-Arie \& Iecovich, 2014). However, in most Western countries home-based care is provided by workers who visit individuals on a daily basis to support them (Genet et al., 2014; Neubert, König, \& Brettschneider, 2018). The current and future availability of this workforce is a source of concern both because demand is increasing due to demographic factors and because the job is deemed to be undesirable, while turnover is high. In England, annual staff turnover rose from 32\% in 2015 to $41 \%$ in 2016 (Holmes, 2016). It has been estimated in Australia that $63 \%$ thirds of carer posts last less than 
two years (Austen, McMurray, Lewin, \& Ong, 2013). Stone et al. (2016) found that $20 \%$ of Canadian home health workers were looking for another job.

Solutions to the pending workforce crisis have been sought by researchers in secondary analysis of large national datasets. In the US, physical injury and perceived racial or ethnic discrimination appear to make it more likely that care workers will leave a job (Jang et al., 2015). We also know that home care has unsociable hours and unreliable pay (Hebson, Rubery, \& Grimshaw, 2015) and that dealing with incontinence is inevitable (Hansen, 2016; Wibberley, 2013). Workers are seen as "an economically disadvantaged group, with modest compensation and poor benefits" (Stone et al., 2016, p. 229). Added to the insecurity of employment, flat career structure and stigma by association with marginalised social groups, all these features make home care a relatively "bad" job (Clarke, 2015). Dementia care can be particularly stressful, raising dilemmas such as whether the carer should always tell the client the truth (Kartalova-O'Doherty, 2014). As an occupation, therefore, home care for people with dementia can be physically onerous, emotionally draining and morally challenging. Yet, as Stone et al., writing about the US survey of home health workers, point out: "it is important to note that respondents reported high levels of satisfaction with the intrinsic aspects of the job, including engagement in challenging work and learning new skills." ( $\mathrm{p} 229$ ). This may be seen as a core paradox in domiciliary care; people frequently find the job rewarding despite its disadvantages. It is reasonable to assume that people who do the job have a distinctive outlook on the work that they do, since their choice of occupation is inconsistent with the prevalent view of caring, reflected in the literature, as unappealing, low status and low paid. This paper therefore investigates the world of home care for people with dementia, from the carers' point of view.

\section{Methodology}

In On Justification (Boltanski \& Thévenot, 2006) political theorists Luc Boltanski and Laurent Thévenot describe the existence of multiple, internally consistent yet distinct moral hierarchies ("orders of worth") that characterise human societies. Each features socially-constructed categories which define right and wrong, good and bad, the righteous and the deviant. In short, different orders of worth reflect distinctive value systems. Boltanski and Thévenot define their orders with reference to five features: guiding principles; driving forces; the objects (concepts and symbols) that are used; what is renounced ("dystopian"); and what is valued ("held up") within that system. In Table 1, this is illustrated with reference to two social systems, called "civic" and "industrial", which frame rival value systems. Social scientists 
Table 1. "Civic" and "Industrial" orders of worth compared (after Boltanski \& Thévenot, 2006).

\begin{tabular}{lll}
\hline Order of worth: & \multicolumn{1}{c}{ Civic } & \multicolumn{1}{c}{ Industrial } \\
\hline Higher common principles & Representative body & Science \\
& The general will & Efficiency \\
& Civil rights & Human potential for activity \\
& Membership & Expertise \\
Driving forces & Solidarity & Quantification \\
& Elections & Production \\
Objects & Policies & Tools \\
& Votes & Resources \\
& Unions & Projects \\
What is renounced & Courts & Systems \\
"dystopian objects" & Individualism & Idleness \\
& & \\
What is held up & Particular interests & Unemployment \\
Who is esteemed & Rule of law & Optimisation \\
\hline
\end{tabular}

have used the orders of worth framework, as its authors intended, to describe, explain and justify the differences that arise when individuals operate within different moral hierarchies (Hanreider, 2016; Jagd, 2011). We follow that tradition here to begin to explore how the subjective world of home carers may differ from that of outsiders.

The overall purpose of the present study was to understand what "good" domiciliary care looks like so that it can be more widely delivered. We draw on data gathered through a programme of home care research called "Broadening our Understanding of Good Home Care" (BOUGH), funded by the National Institute for Health Research School for Social Care Research C088/T14-035. Our focus was the day-to-day practice of home carers, rather than the organisational features of the provider. The design of the research was an ethnographic case study of a commercial home care provider in England. The focus was what makes good home care for people with dementia. We planned to conduct the research in an organisation that was known from previous research to have superior delivery standards and management systems (Jones, 2013). By undertaking the research in a "superior" provider, we sought to "control out" factors, such as very brief visit times or lack of training in dementia care, which present widely-recognised obstacles to good care (Chester, Hughes, \& Challis, 2014; Rodrigues \& Glendinning, 2015). This permitted us to observe the more finegrain features of good home care for people with dementia.

The study collected primary data using five complementary methods. First, two researchers undertook participant observation over ten months in the field, undergoing training and induction to the role and then working parttime as carers in households where a client had dementia. Second, we trained 11 experienced home care workers to keep diaries over 16 weeks. Third, we conducted semi-structured interviews with 14 workers, 6 managers and 15 relatives of current and past clients. Fourth, we surveyed a structured sample of 
commissioners of home care, initially online and then by telephone interview. Fifth, we investigated the home care literature, policy documents and job descriptions. The latter two data sources provide context for the interpretation and extrapolation of findings, but are of less relevance to the present analysis, which aims to understand the world-view of home care workers. In this paper, we draw largely on the first three data sources: interviews and diaries, together with the insights captured by researchers performing the care worker role as participant observers. The employer was compensated for time managers spent on the study. Care workers who kept diaries were paid at their usual rates for up to 16 additional hours, plus the training session. For interviews they were given a $£ 20(\sim 28)$ cash honorarium. The research received ethical approval from the UK Health Research Authority Social Care Research Ethics Committee (Reference 15/IEC08/0043).

\section{Analysis}

The researchers recorded field notes on 334 care visits in seven different households over ten months. Eleven care workers returned diaries with 231 entries totalling over 87,500 words. Interviews were conducted with 14 care workers, which included two of the diarists. All of this data was coded in NViVO 11 (QSR International). The research team read all the transcripts, meeting on several occasions to develop a coding framework and to refine this, starting with the participant observation field notes, then the diary transcripts were added and finally the interview transcripts were coded and integrated. The coding frame continued to evolve through team working and discussion. The entire dataset was subsequently re-read by the lead author from the perspective of the key elements of orders of worth. It was evident that driving forces, objects and dystopian objects accounted for many of the nodes we had previously derived. These were therefore mapped onto the overarching framework offered by Boltanski \& Thevenot's theory, amounting to a second level of analysis. Some nodes were amalgamated to reduce the number of items. For instance "getting clients up or ready for bed" (69 references were coded on this node from 54 separate field notes) and "intimate care" (76 references from 63 sources) became "Personal care/grooming".

In the excerpts that follow, the clients are given pseudonyms beginning with $\mathrm{C}$ and the diarists have pseudonyms beginning with $\mathrm{D}$. To protect anonymity, other people are identified by their roles or unique identifiers which relate to the dataset.

\section{Findings}

From the initial analyses, we divided the activities undertaken by carers into two main categories: practical and social. Applying the order of worth 
framework, both practical and social activities were seen to constitute driving forces of home care in dementia. Practical activities were dominated by meal preparation and management of food or shopping, household chores, recording notes in the daily log, dealing with medication, and supporting clients in personal care. Medication came up frequently as a practical driving force. Promoting choice was the purpose of some practical interventions, such as supporting an individual to choose what to wear. To the extent that the carer had a further intention, such as encouraging the client's individuality, affirming their identity or empowering them, practical activities were sometimes undertaken with a dual purpose; supporting an activity of daily living while reinforcing personhood in some way.

Social activities included outings, watching television or doing puzzles together. Care workers referred to the relational aspect of home care work in their interviews and diaries, while the researchers reflected on it in their field notes. Our initial codes identified 20 types of social activity undertaken by care workers. The most densely-populated code was "chatting", which often accompanied practical tasks, like washing and dressing, and served different purposes, including: retaining the attention of the client with dementia; making mundane tasks more agreeable; and diverting attention from the embarrassment involved in carrying out personal or intimate care - aspects of emotional labour (Bailey, Scales, Lloyd, Schneider, \& Jones, 2015). The importance of chatting may be seen in the counterfactual example given here:

[Co-worker] told me that Christine is not like other clients she visits as you don't really build up a rapport with her. She stressed, it's not that she's unfriendly, she's just not interested in chatting: she is very 'as you are dear'. [Co-worker] said that even if you visited her every day for a couple of years, you probably wouldn't be able to build up much rapport either. (Researcher 812 15)

The nature of dementia means that the social activity of relationshipbuilding and maintenance are usually led by the care giver; in certain situations this may be regarded as "performing", another form of emotional labour.

Whenever Claire repeats a story, I act as if it is new, and try and perform laughter and enthusiasm and all the necessary emotions. Yet this is very much a performance because it is actually a little frustrating and annoying to hear the same story so many times. (Researcher 0404 16)

When relationships worked well, affectional bonds grew between the care worker and clients, and these were often mutual. In the following extract, this is implicit in the tone with which the diarist writes, but it is also expressed in the attention to detail and empathic approach adopted. Of course, in interpreting the diaries, one has to recognise that there is a performative aspect to what people wrote. Diarists were likely to be concerned, to a greater or lesser 
extent, with presenting themselves as "good" care workers, who are effective and well-liked by clients and their families.

I dressed him as warm as possible as mid- winter + perishing outside. My first action was increasing the central heating thermostat. After breakfast I settled him cosy in his lounge chair and before I left the house he was fast asleep in his chair, no doubt exhausted after our own efforts + being in hospital with heart failure + a serious chest infection. (Deidre's diary)

While close relationships were often forged through long-term familiarity with clients, strong bonds brought corresponding risks of bereavement and loss to those workers who invested in their relationships with clients. Yet it was apparent from interviews that care workers overcame losses and started work with other clients fairly easily, seeing this kind of adaptation as an inevitable part of the job, even when close bonds had been forged:

Feeling quite sad today not heard from the family of my client who passed away, I would have liked to attend her funeral or send flowers as she loved them but I have to respect her family's wishes, I have bought some daffodils for home to remember her by. I do feel downhearted. I really did go the extra mile for this client, feel very undervalued, I love my job \& don't expect too much, but when you have dedicated so much \& put so much in, a thank you means so much. (Dee's diary)

An important phrase is used here; "going the extra mile" was deployed in the organisation to indicate the standard of dedication that was expected of care workers, putting the client above their own needs. We were informed in interviews with home care staff that going the extra mile was held up as measure of good quality care. The significance of this phrase in the diary is therefore strengthened by its meaning within the organisation as something that is "held up" or valued.

The care workers sometimes initiated pleasurable activities, such as outings, board games, looking at family snapshots and other shared activities such as gardening or reading the newspaper. Implicit in this approach is an understanding of the benefits such may have for social wellbeing as well as cognition, overall functioning and quality of life.

The mornings were a delight. I gave her breakfast in bed and she would often sing, it was lovely to hear her. I then spent time helping her with personal and medical care. After this she would have a cup of tea while I did household jobs. In the afternoons, either I took her on an outing to a town, garden centre or similar or twice a week she went to ... a club providing lunch, activities and support for clients with memory loss. (Deirdre's diary)

While there are often limitations on the resources available, facilitating clients to interact socially was a source of great satisfaction for care workers, who found the outings a highlight of their work routine. 
Domiciliary care that responds to the driving forces of promoting socialisation through meeting people outside the home, or of providing pleasure and mental stimulation, is likely to be far better for people with dementia. More can be discovered about driving forces from the instances where efforts by the care worker were frustrated in the following excerpt. The key task here was companionship, but this visit the carer turns to practical tasks to fill her time and to encourage the client to undertake some activity:

A very trying day. Cassie not happy when I arrived and commenting that she didn't see any need for anyone to be with her and couldn't remember if she'd had any carers in the past. Reassured her that her sons felt she needed some company. She said she wanted time on her own and I told her that between 11.30am \& 4pm she was on her own each day. She said 'good' because then she could do what she wanted. ... I suggested I vacuum, more to have something to do than out of need, and once I started she decided to dust \& watered the plants. (Dorothy's diary)

One reading of this text is that, even when the client was unco-operative, the carer's knowledge of a client's preferences and behaviour patterns, built up through careful observation over time, could be used complete the care mission.

Turning to the "dystopian" elements that characterise an order of worth, in our analysis many of these are inverse to the driving forces. Fear of falls was a frequent theme, because of the likelihood of fractures, and the pain and disability that was likely to ensue. We may also infer from the quotations presented here and throughout the dataset that dirt, decay and disease were disliked by care workers. Adverse care experiences could potentially be dystopian objects. We found that care workers blamed themselves when they were unable to accomplish what they set out to do in a difficult care episode:

Her Alzheimer's progressed quite rapidly. And she ended up having her bedroom downstairs but becoming exceedingly, verbally aggressive, exceedingly rude, refused to get out of bed if you're doing a morning visit, refused to go to bed if you were doing the evening visit. And you used to come away, sometimes, you'd have to ring the door just said, Look, I'm sorry, seven o'clock, the visit, she's not gone to bed, she doesn't want to go to bed, she's shouting at you to leave her house, and the daughter would say, Go. But of course, you'd go home thinking 'I've failed'. (Care worker interview B04)

This deprived the care worker of the expected reward - the satisfaction of a job well done. Her regret signals that this element is an important consideration in the care worker world. Even challenging clients were seen as rewarding when small acts of compliance and co-operation could be perceived and "taken home" to give some satisfaction of a job well done.

Relatives' interactions with people with dementia could also present problems and thwart efforts to promote best practice in dementia care. For 
instance, a skilled carer would not challenge a person with dementia by asking questions they clearly cannot answer:

Whilst we were sat at the table, [client's niece] was discussing where she has lived and the various houses she had owned. ... [Niece] kept giving prompts, for instance: "you must remember, the house we had the two children in" etc; however Claire appeared not to recall any of the previous houses [niece] had lived in. The niece, through the tone of her voice, and repetition of phrases such as "you must remember", appeared to be becoming increasingly frustrated and upset at Claire's memory problems. (Researcher 31215 )

There could also be tensions between the relatives and the worker:

I feel I am 'walking on egg shells' during the visits since 2 weeks [client's] daughter telephoned the care management and said the toilets are not being cleaned sufficiently. I tend to do everything to a high standard and find it hard to have enough time during the one hour visit to achieve as much as I would like and the perfection I would like and I believe the other carers visiting feel the same. (Deidre's diary)

In such family situations, where there were disputes between relatives over a client or between relatives and clients, the care worker had to exercise tact and discretion. It was clear from the data that workers felt that it was a valid part of their role to facilitate the social and family roles of their clients; for example, one diarist said that she helped her client to bake a cake in advance of a family visit. This work affirmed and reinforced the client's social identity and roles even when she could not initiate this alone (Sabat \& Harré, 1992).

\section{Application of the theoretical framework to our data}

Table 2 maps the concepts derived from the work of home care onto the framework provided by Boltanski and Thévenot, to illustrate the distinctive characteristics of good home care. To begin with, the "objects" that feature in the world of home care and appeared frequently in the fieldnotes: smiles, medication, compliments, cards and gifts figured in the data as items that populate the world of home care. These also included the care log, the cup of tea, the meal or snack, the laundry, the toilet (which requires frequent cleaning), the bed, the shower, and the clothes in which the client is dressed. The objects associated with the task of home care in dementia are mostly mundane necessities (food, cups of tea) and social symbols (smiles, gifts) as listed in Table 2. One object that is distinctive of the care function is the care $\log$, the record of interactions in the home. The importance of this is expressed in the often-cited expression “...if it isn't written down, it didn't happen". An accurate and up-to-date care log is an important object in the home care workers' order of worth because it is often the only hard evidence of their labour. 
Table 2. Domiciliary dementia care - the carers' order of worth.

\begin{tabular}{|c|c|}
\hline Higher common principles & $\begin{array}{l}\text { Value \& worth of individual } \\
\text { Empathy } \\
\text { Preserving life }\end{array}$ \\
\hline Driving forces & Chatting \\
\hline Social & $\begin{array}{l}\text { Relationship building } \\
\text { Reciprocity } \\
\text { Having a laugh } \\
\text { Affection/attachment } \\
\text { Preparing and offering food }\end{array}$ \\
\hline Practical & $\begin{array}{l}\text { Promoting agency and choice } \\
\text { Personal care/grooming } \\
\text { Housework } \\
\text { Attending to medication }\end{array}$ \\
\hline Objects & $\begin{array}{l}\text { Medication } \\
\text { Food } \\
\text { Smiles, hugs } \\
\text { Cups of tea } \\
\text { Compliments } \\
\text { Gifts } \\
\text { Care plan/log of activity }\end{array}$ \\
\hline What is renounced - "dystopian objects" & $\begin{array}{l}\text { Risks and falls } \\
\text { Failure to meet a client's needs } \\
\text { Inconvenient relatives } \\
\text { Dirt, decay } \\
\text { Disease, death }\end{array}$ \\
\hline What is held up & $\begin{array}{l}\text { Being dedicated, going the extra mile } \\
\text { Being appreciated, recognition } \\
\text { Hygiene and health }\end{array}$ \\
\hline Who is esteemed & The client \\
\hline
\end{tabular}

We have seen from the data presented here that the "driving forces" of the job include practical tasks of preparing meals, administering medication, household chores, and personal care for clients. Remembering what to do and recalling a given client's preferences calls for good organisation, attention to detail, and forward planning. Indeed, anticipating a person's needs emerges as a key skill in dementia home care. Several excerpts reveal that the worker is "thinking ahead" and making provision for future eventualities, as well as enabling a client to exercise agency through choice. Our data show how, in this context, personal agency is supported through the management of practical activities. The skill and sensitivity with which these activities are performed reflect the worker's active regard for the individual client.

There are also social driving forces; they can be grouped together under the heading of "relationship-building". These include chatting, observation, laughing, sharing common ground. A particular skill of good dementia care seems to include using practical tasks to meet social needs, but with an eye to seizing opportunities for promoting mental activity in people with dementia. Where possible, good home care appears to have as its aim a client's enjoyment, whether this is through a refreshing shower, a comforting meal, or a trip out. 
For experienced dementia home care workers, a further purpose of relationship-building is, where possible, to reinforce the client's social identity by facilitating social engagement. This may involve reciprocity of marking special occasions like birthdays and anniversaries. To achieve this effectively the care worker needs to have a clear understanding about where the client fits into a social network and how they prefer to function in that network.

Care workers demonstrated through our data a remarkable amount of tact and social skill to avoid embarrassing or humiliating clients who had memory lapses or were incontinent, for example. Diplomatic skills may also be needed, particularly in dealing with relatives, who may be operating from a different set of assumptions from the care worker. In the UK, job descriptions do not specify the complex social skills and deep understanding of norms demonstrated by care workers in this context. While interpersonal skills may be ascertained at some point in the recruitment process, through individual or group interviews, and personal attitudes, including "respect" and "person-centredness", are sometimes specified in publicity material, there is a clear gap between the level at which good home carers operate and the entry-level job requirements.

"Dystopian objects" can be inferred from the efforts of the care workers to counteract them: loneliness, sickness, death, dirt, disease, discomfort or distress. In particular, falls have a symbolic meaning as a sign of poor care practice and because the sequelae can be disastrous for frail older people. Aggressive or unco-operative clients are problematic and may sometimes be dystopian because this makes the care process tricky and unsatisfying for most workers, who would generally prefer to be able to demonstrate a material improvement in the client's wellbeing at the end of a visit. Relatives can sometimes present an inconvenience, especially if they lack insight or do not subscribe to the same care values as the worker. Relatives who transgress social boundaries may fall into the category of negative or dystopian objects.

The tension between driving forces and dystopian objects throws into relief those "things that are held up" within the world of home care workers in dementia care. These elements correspond to the standards to which the care workers aspire. For instance, ingratitude is a dystopian object; conversely, affection and recognition are by implication valued or "held up". Dirt and disease are anathema; by implication hygiene and health are valued. Working to provide a service despite the care worker's personal inconvenience - sometimes referred to in the organisation as "going the extra mile", was also held up by the carers. For instance, field notes documented numerous examples of workers staying beyond their allocated (paid) time because they judged this to be important to the client's interests. 


\section{Discussion}

This analysis has implications for all those people responsible for personal care in the home of a person with dementia. This includes paid carers themselves, as well as the people who contract their services. Domiciliary care employers, trainers and policy makers can also gain insights from this analysis, which seeks to address the central paradox of home care for people with dementia: why low-paid carers do the job despite its disadvantages. The application of the theoretical framework has enabled us to draw out from ethnographic data a comprehensive description of the subjective world of home care workers for people with dementia in terms of the system of values that they operate, the objects they use, and the goals that motivate them.

In the moral hierarchy of home carers, of paramount importance is the value of the individual, irrespective of mental capacity. The preservation and maintenance of that person's physical, mental and emotional wellbeing follow from this principle. Recruiters need to consider where they will find workers whose own values are consistent with this approach. Nursing, child care, teaching and other caring professions are likely to offer a suitable preparation for domiciliary care work. Some employers target religious communities to attract idealistic individuals who are eager to serve.

While they aspire to prioritise the person with dementia, receiving recognition for what they do seems to be part of the implicit moral balance in home care. This analysis also enables an outsider to understand how important it is for care workers to be able to achieve an improvement in the client's wellbeing, however small. Employers who seek to retain staff could do well to attend to the needs for achievement and for recognition that have been highlighted here. Effective mechanisms for empowering care workers and for rewarding their endeavour may have implications for the retention of staff in a high-turnover environment.

The social skills of care staff and their appreciation of an individual's social and cultural roles emerged as key factors in the social interactions that they often had to initiate in dementia care. We might call this emotional intelligence, and it is clearly a desirable qualification for the role. Some providers allow for this in the careful matching of clients to care staff. However, where this is not possible, the empathy of care workers for their clients' preferences and social needs is something that could potentially be developed through training. The frequent occurrence of loss and separation from clients may also be something for which preparation can be made in training. Organisation may be advised to address this in a formal way through some formal memorialisation of departed clients. 


\section{Limitations}

The data were generated in a single organisation and location, with a small number of households observed (6), and a self-selected group of care workers kept diaries or were interviewed for the study. The perspective of the analysis is limited by this context. The domiciliary care organisation was a superior provider and not dogged by the need to deliver care in small segments of time or without sufficient staff. This may be taken to mean that the data are effectively unmarred by the resource constraints that create additional tensions in dementia care settings.

\section{Conclusion}

The overarching research question "what does 'good' home care look like in dementia?" has been answered here from the point of view of care workers. We have elaborated on their values and moral hierarchy. This knowledge may be applied to help to tackle the need for more care workers who are suited to the challenging demands of domiciliary dementia care. It also demonstrates the high level of emotional intelligence and social skills that care workers deploy to deliver good home care for people with dementia. That may serve to set a standard for the quality of domiciliary dementia care in other contexts.

\section{Disclosure statement}

No potential conflict of interest was reported by the authors.

\section{Funding}

This work was supported by the National Institute for Health Research [School for Social Care Research C088/T14-035].

\section{ORCID}

Nicola Turner (D) http://orcid.org/0000-0002-0870-8324

\section{References}

Austen, S., McMurray, C., Lewin, G., \& Ong, R. (2013). Retaining workers in an ageing population: Insights from a representative aged and community care organisation. Australasian Journal on Ageing, 32(1), 41-46. doi:10.1111/j.1741-6612.2012.00599.x

Bailey, S., Scales, K., Lloyd, J., Schneider, J., \& Jones, R. (2015). The emotional labour of health-care assistants in inpatient dementia care. Ageing \& Society, 35(2), 246-269. doi:10.1017/S0144686x13000573

Ben-Arie, A., \& Iecovich, E. (2014). Factors explaining the job satisfaction of home care workers who left their older care recipients in Israel. Home Health Care Services Quarterly, 33(4), 211-228. doi:10.1080/01621424.2014.956958 
Boltanski, L., \& Thévenot, L. (2006). On justification. The economies of worth. Princeton: Princeton University Press.

Chester, H., Hughes, J., \& Challis, D. (2014). Commissioning social care for older people: Influencing the quality of direct care. Ageing \& Society, 34, 930-950. doi:10.1017/ S0144686X12001249

Clarke, M. (2015). To what extent a "bad" job? Employee perceptions of job quality in community aged care. Employee Relations, 37(2), 192-208. doi:10.1108/er-11-2013-0169

Genet, N., Boerma, W., Kroneman, M., Hutchinson, A., \& Saltman, R. B. (2014). Home Care across Europe: Current structure and future challenges. Retrieved from Geneva.

Hanreider, T. (2016). Orders of worth and the moral conceptions of health in global politics. International Theory, 8(3), 390-421. doi:10.1017/S1752971916000099

Hansen, A. M. (2016). Rehabilitative bodywork: Cleaning up the dirty work of homecare. Sociology of Health \& Illness, 38(7), 1092-1105. doi:10.1111/1467-9566.12435

Hebson, G., Rubery, J., \& Grimshaw, D. (2015). Rethinking job satisfaction in care work: Looking beyond the care debates. Work Employment and Society, 29(2), 314-330. doi:10.1177/0950017014556412

Holmes, J. (2016, May). An overview of the domiciliary care market in the United Kingdom. Retrieved from.

Jagd, S. (2011). Pragmatic sociology and competing orders of worth in organizations. European Journal of Social Theory, 14(3), 343-359. doi:10.1177/1368431011412349

Jang, Y., Lee, A. A., Zadrozny, M., Bae, S.-H., Kim, M. T., \& Marti, N. C. (2015). Determinants of job satisfaction and turnover intent in home health workers. Journal of Applied Gerontology, 36(1), 56-70. doi:10.1177/0733464815586059

Jones, R. (2013). Improving effective integrated home support for people with dementia and their carers. Retrieved from.

Kartalova-O'Doherty, Y. (2014). Dementia - What is truth? Exploring the real experience of people living with more severe dementia. A Mental Health Foundation national inquiry. Retrieved from London: https://www.mentalhealth.org.uk/sites/default/files/Dementia\% 20truth\%20inquiry\%20lit\%20review\%20FINAL\%20(3).pdf

Neubert, L., König, -H.-H., \& Brettschneider, C. (2018). Seeking the balance between caregiving in dementia, family and employment: Study protocol for a mixed methods study in Northern Germany. BMJ open, 8, e019444. doi:10.1136/bmjopen-2017-019444

Prince, M., Bryce, R., Albanese, E., Wimo, A., Ribeiro, W., \& Ferri, C. P. (2013). The global prevalence of dementia: A systematic review and metaanalysis. Alzheimers \& Dementia, 9 (1), 63-75. doi:10.1016/j.jalz.2012.11.007

Rodrigues, R., \& Glendinning, C. (2015). Choice, competition and care - developments in english social care and the impacts on providers and older users of home care services. Social Policy \& Administration, 49(5), 649-664. doi:10.1111/spol.12099

Sabat, S. R., \& Harré, R. (1992). The construction and deconstruction of self in Alzheimer's disease. Ageing and Society, 12(4), 443-461. doi:10.1017/S0144686X00005262

Skills for Care. (2017) The state of the adult social care sector and workforce in England, 2017 published by skills for care, west gate, 6 grace street, Leeds LS1 2RP. Retrieved from www. skillsforcare.org.uk

Stone, R., Wilhelm, J., Bishop, C. E., Bryant, N. S., Hermer, L., \& Squillace, M. R. (2016). Predictors of intent to leave the job among home health workers: Analysis of the national home health aide survey. The Gerontologist, gnw075. doi:10.1093/geront/gnw075

Wibberley, G. (2013). The problems of a 'dirty workplace' in domiciliary care. Health \& Place, 21, 156-162. doi:10.1016/j.healthplace.2013.01.014 